\title{
Tobacco Consumption in Some Traveling Agencies in Bafoussam in West Region Of Cameroon, Associated To Mouth Cytology and Malondialdehyde (MDA) Profile
}

\author{
K. D. Kambou Kountchou, A. Tamuedjoun Talom, A. L. Deutou Wondeu, J.-R. Kuiate
}

\begin{abstract}
ABASTRACT
Tobacco is mostly regarded as one of the primary etiologic factor in causing oral cancer. Its use affects the pattern of maturation in oral mucosal cells and results in changes in the appearance of the tissues. Lipid peroxidation (LPO) has been implicated in the pathogenesis of several pathologic disorders, including oral premalignant and malignant lesions. The aim of this study was to determine the prevalence of tobacco use and assess its effects on oral epithelial cells and oxidant/antioxidant balance in the oral cavities of tobacco consumers in some travelling agencies in Bafoussam West Region Cameroon.

A cross sectional study with a total of 120 individuals (divided into two groups; group $A(n=55)$ including non-consumers of tobacco above 21 years old and group $B(n=65)$ including tobacco consumers above 21 years old), voluntarily enrolled in the study. After giving their consents and answering a series of questions from questionnaires, saliva samples and buccal smears were collected from their oral cavities. Buccal smears were stained using Papanicolaou staining technique and the presence of hyperkeratosis, tobacco hyperkeratosis, non-specific inflammatory changes and oral microflora were assessed. [MDA] was determined using the Thiobarbituric acid method. The results showed that male tobacco consumers made $48.3 \%$ and most of them were aged between 21-31 years old, while female tobacco consumers made $5.7 \%$ of the total sample population. Smoking was the method most used by consumers $(41.7 \%)$ and $66 \%$ of them smoked for more than 10 years while $50 \%$ smoked more than 10 sticks of cigarette per day. A statistical significant relationship was found between tobacco consumption and oral epithelial changes $(p<0.001)$. Only tobacco consumers presented with tobacco hyperkeratotic buccal smears $(20 \%)$ when compared with the control group. A good number of hyperkeratotic buccal smears (39.2\%) was found in both the case (17.5) and control (21.7\%) groups. $24.1 \%$ of the total sample population had normal buccal smears, where $8.3 \%$ were consumers and $\mathbf{1 5 . 8 \%}$ were non-consumers. Microorganisms were found on buccal smears of $\mathbf{5 . 9 \%}$ of individuals and $9.2 \%$ had non-specific inflammatory changes. Between tobacco consumption and salivary [MDA] in saliva of tobacco consumers was significantly higher compared to non-consumers $(\mathbf{p}<0.001)$. A strongly positive correlation was found between salivary [MDA] and oral epithelial changes $(r=0.204, p=0.026$ at $0.05 \mathrm{CI})$. In conclusion, tobacco consumption severely increases the risk for developing oral mucosal proliferative lesions, and the level of oxidative stress in the saliva of individuals in the study population.
\end{abstract}

Key words: Cigarette smoking, Oxidative stress, Malondialdehyde, Premalignant lesion, Oral squamous cell carcinomas.

\section{INTRODUCTION}

Tobacco use is harmful and often results in serious adverse health problems. It is a delivery system for the addictive agent nicotine. While there are many different forms of tobacco (cigarettes, cigars, cigarellos, beedis, kreteks, pipe tobaccos and smokeless products), the most common is the manufactured cigarette. In 2015, the prevalence of tobacco
Published Online: July 21, 2020.

ISSN: $2684-4443$

DOI: $10.24018 /$ ejdent.2020.1.4.11

K. D. Kambou Kountchou

Laboratory of Anatomy and Cytopathology, Faculty of Science and Technologies, Evangelical University of Cameroon, P.O Box : 127 Bandjoun-Cameroon.

(kountchou3@yahoo.com)

\section{A. Tamuedjoun Talom}

Laboratory of Anatomy and Cytopathology, Faculty of Science and Technologies, Evangelical University of Cameroon, P.O Box : 127 Bandjoun-Cameroon. (alaric.talom@uecam.org)

\section{A. L. Deutou Wondeu}

Laboratory of Anatomy and Cytopathology, Faculty of Science and Technologies, Evangelical University of Cameroon, P.O Box : 127 Bandjoun-Cameroon.

(laure.chouamou@uecam.org)

\section{J.-R. Kuiate*}

Laboratory of Anatomy and Cytopathology, Faculty of Science and Technologies, Evangelical University of Cameroon, P.O Box : 127 Bandjoun-Cameroon.

Research Unit of Microbiology and Antimicrobial Substances, Faculty of Science, University of Dschang, PO Box 67 DschangCameroon.

(jrkuiate@uecam.org or jules.kuiate@univdschang.org)

*Corresponding Author smoking in the world was estimated to be more than 1.1 billion, with males more than females. Although tobacco smoking is globally declining, its prevalence appears to be increasing in the Eastern Mediterranean and the African Regions [1]. It is well established that tobacco use plays a major role in the etiology of several cancers particularly oral cancer [2], [3]. People play an important role in the beginning and the continuation of tobacco consumption. Family, friends 
and role models influence smoking behavior. Young people who have smokers around them are particularly at greater risk of starting to smoke. In adolescence, cigarettes can also be used as a way to rebel against one's parents or to belong to a group. Stress related to working conditions is also a factor that increases the risk of starting to smoke. Tobacco advertising also promotes the consumption of cigarettes. Tobacco advertising aimed at children and adolescents is very widespread and has the effect of trivializing tobacco consumption. All these conditions are perfectly met in travel agencies where there are influencers, working conditions and harsh stress as well as promiscuity.

The relationship between oral cancer and tobacco consumption is well documented, but other oral changes are known to occur with tobacco use [4]. Worldwide, it is estimated that an incidence of approximately 274,300 and mortality rate of 127,500 are attributed to cancer of the oral cavity during 2002 [5]. In the developing countries like Cameroon, cancer is one among the ten commonest causes of mortality. This cancer epidemic is due to the combined effect of increased life expectancy and the high or increasing levels of prevalence of cancer risk factors. Tobacco use can irritate the minor salivary glands on the hard palate and directly increase a person's risk for periodontal disease and oral cancer. Oral cancer causes serious morbidity and mortality in older adults [6]. It is predominately a disease of middle-aged men who use tobacco and alcohol. Approximately 95\% of carcinomas appear after age 45 years, with an average age of 60 years. Most oral cancers are squamous cell carcinomas, and the vast majority of oral squamous cell carcinomas (OSCC) are preceded by precursor lesions that can present as leukoplakia, erythroplakia, or erythroleukoplakia [6]. Microscopically, these lesions may exhibit oral epithelial dysplasia, a histopathologic diagnosis characterized by cellular changes and maturational disturbances indicative of developing malignancy. Oral cytology is not done in our country that is why patients come with already advanced lesions. Cigarette pyrolysis produces smoke containing combustion byproducts and free radicals which have been defined as carcinogenic. These free radicals can and do react with other additives or other pyrolytic products or living cells and cause DNA damage [7], [4]. ROS and free radicals primarily target peroxidation of polyunsaturated fatty acids (PUFAs) in membrane lipids [7]. They also interact with cellular DNA causing DNA damage and interference with its repair, which is a major cause of pathobiological changes in cancer cells. Peroxidation of membrane lipids generates well characterized, mutagenic lipid peroxidation end products, such as Lipid. Thus, the aim of this study is to assess the effect of tobacco on buccal epithelial cells and oxidant/antioxidant balance in the oral cavities of tobacco smokers in Bafoussam West Region Cameroon.

\section{METHODS}

This study was carried out based on the ethical approval from the National Ethical Committee for Research and Human Health in Yaoundé, Cameroon, reference $\mathrm{N}^{\circ}$ 2019/06/37/CE/CNERSH/SP. It was carried out from April 2019 to September 2019 in the dental service of the regional hospital of Bafoussam and in 10 travelling agencies in Bafoussam, West Region of Cameroon. One hundred and twenty (120) subjects of both genders were recruited, 32 from regional hospital and 88 from travelling agencies. The subjects ranged in age from 21 years and above and were categorized into two groups; 55 non consumers of tobacco who constituted the control group and 65 consumers of tobacco who constituted the study (case) group. Were excluded subjects who denied to provide saliva and buccal smears samples after answering questionnaire. Buccal smears were used to assess oral cellular characteristics of premalignant lesions while saliva samples were used to determine the level of MDA in the mouth. Written informed consent was obtained from the patients, after the planned study was explained in detail.

\section{A. Administration of questionnaire}

The questionnaire was structured into demographic data (age, gender, and profession), specific questions on tobacco consumption, method of consumption, and duration of consumption. Participant's medical history and dental history were assessed, where diabetes, hypertension, HIV/AIDS, leukemia, pregnancy, breast feeding, dental caries, gingivitis, periodontal diseases and any other pathology present were checked from hospital books (when applicable) and questions.

The data sheet was structured into three (03) parts including macroscopic analysis, microscopic analysis and MDA determination. Macroscopically, the presence of lesion, location, dimensions, color and aspect of the lesion were determined. Microscopically, the presence of hyperkeratosis, tobacco hyperkeratosis, non-specific inflammatory changes and microflora were assessed. MDA concentration was determined using the thoibarbituric acid method and the optical density was read from a spectrophotometer at $532 \mathrm{~nm}$.

\section{B. Detection of cytological abnormalities}

- Buccal smear sample collection and processing

Oral exfoliative cells were collected from the buccal mucosa (covering both cheeks) and any other suspicious areas, using wooden tongue depressors, and the material obtained were directly smeared on clean labelled glass slides and immediately fixed using a cytofixative spray (materials purchased from POLYPHARMA). The fixed slides were taken to the cytopathology laboratory of the university (Cameroon Evangelical University)

At the cytopathology laboratory of the Evangelical University of Cameroon, the slides were stained using the Papanicolaou staining technique [22]. The slides were then observed under the light microscope to look for cellular changes like dysplasia, dyskeratosis, parakeratosis, 
hyperkeratosis, hypergranulosis (cytoplasmic granulosis), basal cell hyperplasia, binucleation, perinuclear hallos, nuclear enlargements, as well as the presence of oral microflora and inflammation. A normal buccal smear was defined as on which superficial and intermediate cells are well represented, with a clear background (i.e. absence of microorganisms, inflammatory cells, debrises...) Parakeratotic cells where keratinized small superficial squamous cells with persistent picknotic nuclei. Shapes vary from round or oval to polygonal or spindle shaped. Cytoplasmic staining usually is dark or light eosinophilic, rarely cyanophilic. They can be isolated or in plaques or sheets. It shows anucleated single cells with cells with nonrefractive pink yellow, or orange cytoplasm and plaques of anucleate cells. On this image is also found epithelial cells with granules in their cytoplasms, similar to cells of the granulated layer of an epidermis.

- Detection of oxidative stress levels

To minimize diurnal variations, saliva samples were collected in the morning (from 08am to 10am). Unstimulated saliva pooled in the floor of the mouths was collected by asking the patient to spit in a sterile labelled glass tube. These samples were stored at low temperature in glass flask and immediately transported to the laboratory for analysis. The concentration of MDA was determined using the Thiobarbituric acid method [21]. In glass tubes, $0.3 \mathrm{ml}$ of collected saliva was mixed with $3 \mathrm{ml}$ of $0.025 \mathrm{M}$ Tris-HCL and $0.175 \mathrm{M}$ KCL buffer at a $\mathrm{pH}$ of 7.4. The mixtures were centrifuged at $4000 \mathrm{~g}$ for 10 minutes and both the precipitates and supernatants were stored in the school laboratory freezer.

- $\quad$ Saliva sample processing

The determination of MDA was done as follows; in dry glass tubes, five hundred microliters $(500 \mu \mathrm{l})$ of $1 \%$ orthophosphoric acid and $500 \mu \mathrm{l}$ of precipitation mixture $(1 \%$ thiobarbituric acid in $1 \%$ acetic acid) were added to $100 \mu \mathrm{l}$ of homogenate (sample + Tris HCL-KCL buffer). The mixture of each tube was homogenized by vortexing and passed on a boiling water bath at $95^{\circ} \mathrm{c}-100^{\circ} \mathrm{c}$ for 15 minutes. The tubes were then cooled in an ice bath and the mixture was centrifuged at $3500 \mathrm{~g}$ for 10 minutes. The absorbance of the supernatants was read at $532 \mathrm{~nm}$ against the control. Lipid peroxidation was calculated on the basis of the MDA molar extinction coefficient and expressed in micromoles of MDA per milliliter of sample using the Lambert-Beer formula where $\mathrm{DO}=\varepsilon \mathrm{LC}$.

\section{Statistical analysis}

Data was statistically analysed using SPSS. MDA raw data were subjected to the one-way ANOVA analysis of variance and to using the Waller-Duncan test at 0.05 Confidence Interval (CI). Demographic data, prevalence, duration and quantity of tobacco consumption and oral epithelial changes were described in terms of percentages and were subjected to the Chi Square statistical test at 0.05 CI. The Pearson correlation was used to research the degree of links between the various quantitative parameters at the threshold of 0.05 or 0.01 .

\section{RESULTS AND DISCUSSION}

\section{A. General characteristics of the study population}

The study population consisted of 120 subjects including $91(54.2 \%)$ of men and $55(45.8 \%)$ of women (Table 1$)$. The most represented age group was that of [21-31] years consisting of $36(30 \%)$ people including 29 (24.1\%) men for $7(5.8 \%)$ women. The least represented age groups were [6171 [and $>71$ years old, with $54.2 \%$ ) and $1(0.8 \%)$ respectively. In terms of medical history, the majority of participants (84 $(70 \%)$ ) declared that they had no known health problems, with up to $66(55 \%)$ men for only $18(15 \%)$ of women. However, $18(15 \%)$ of participants had gastritis including. Only 10 $(8.3 \%)$ participants were hypertensive, equally distributed between men and women. Regarding dental history, 59 $(49.2 \%)$ of the participants had no known problems while gingivitis and periodontitis $(20 ; 16.7 \%)$, plaque and calculus $(18 ; 15 \%)$ and dental caries $(14 ; 11.7 \%)$ were the most common diseases in the study population.

TABLE 1. GENERAL CHARACTERISTICS OF THE STUDY POPULATION

\begin{tabular}{|c|c|c|c|}
\hline Characteristics & $\begin{array}{l}\text { Male } \\
\mathbf{n}(\%)\end{array}$ & $\begin{array}{c}\text { Female } \\
\mathbf{n}(\%)\end{array}$ & $\begin{array}{c}\text { Numbers } \\
\mathbf{n}(\%)\end{array}$ \\
\hline \multicolumn{4}{|l|}{ Age ranges (years) } \\
\hline$[21-31]$ & $29(24,1)$ & $7(5,8)$ & $36(30)$ \\
\hline [31-41] & $18(15,0)$ & $5(4,2)$ & $23(19,2)$ \\
\hline$[41-51]$ & $19(15,8)$ & $6(5,0)$ & $25(20,8)$ \\
\hline [51-61] & $21(17,5)$ & $9(7,5)$ & $30(25)$ \\
\hline$[61-71]$ & $4(3,3)$ & $1(0,8)$ & $5(4,2)$ \\
\hline$\geq 71$ & $0(0)$ & $1(0,8)$ & $1(0,8)$ \\
\hline Total & $91(75,8)$ & $29(24,2)$ & $120(100)$ \\
\hline \multicolumn{4}{|l|}{ Medical history } \\
\hline $\begin{array}{l}\text { Healthy (No known health } \\
\text { problems) }\end{array}$ & $66(55.0)$ & $18(15.0)$ & $84(70)$ \\
\hline Hypertension & $5(4.2)$ & $5(4.2)$ & $10(8.3)$ \\
\hline HIV/AIDS & $0(0.0)$ & $1(0.8)$ & $01(0.8)$ \\
\hline On medications & $1(0.8)$ & $2(1.6)$ & $03(2.5)$ \\
\hline Pregnancy & - & $1(0.8)$ & $01(0.8)$ \\
\hline Gastritis & $17(14.2)$ & $1(0.8)$ & $18(15.0)$ \\
\hline Diabetes and hypertension & $2(1.6)$ & $1(0.8)$ & $03(2.5)$ \\
\hline \multicolumn{4}{|l|}{ Dental history } \\
\hline $\begin{array}{l}\text { Healthy oral cavity (No } \\
\text { known oral health } \\
\text { problems) }\end{array}$ & $45(37.5)$ & $14(11.7)$ & $59(49.2)$ \\
\hline Dental caries & $12(10.0)$ & $2(1.7)$ & $14(11.7)$ \\
\hline $\begin{array}{l}\text { Gingivitis and } \\
\text { periodontitis }\end{array}$ & $14(11.7)$ & $6(5.0)$ & $20(16.7)$ \\
\hline Plaque and calculus & $14(11.7)$ & $4(3.3)$ & $18(15.0)$ \\
\hline $\begin{array}{l}\text { Dental caries, gingivitis } \\
\text { and periodontal diseases }\end{array}$ & $5(4.2)$ & $3(3.3)$ & $08(6.7 a ̀$ \\
\hline Apical abscess & $1(0.8)$ & $0(0.0)$ & $01(0.8)$ \\
\hline
\end{tabular}

\section{B. Distribution of tobacco consumption according to population characteristics}

Tobacco use was higher among men $(48.3 \%)$ than women $(5.8 \%)$. This consumption was unevenly distributed across the different age ranges. Thus, in men, tobacco consumers were more recruited in the age groups of [21]-[31], [41]-[51] and [51]-[61] years, while in women they were mostly in the age groups [41]-[51] and [51]-[61]. The difference of tobacco consumption according to age range in each sex was not 
significant while the tobacco use was significantly higher in men compared to women $(\mathrm{p}=0.0001)$.

Among tobacco users, four methods of consumption were identified: smoking, inhaling, chewing and application on the teeth (Table 2). The last two methods were combined to smoking only in men: smoke + inhale $(9.2 \%)$ and smoke + chew (6.1\%). Tobacco smokers (76.9\%) were most represented in the study population, with $73 \%$ of men and only $3.1 \%$ of women. Smokers were significantly more represented $(\mathrm{p}=0.001$ in male population. These smokers are mainly recruited in the age group of [21]-[31] and [61]. Very few participants admitted to applying tobacco on their teeth (7.7\% of women against $3.1 \%$ of men). The vast majority of smokers $(66 \%)$ have been smokers for more than 10 years and are recruited in the age groups of [41-51] and [51-61] which represent respectively $24 \%$ and $26 \%$ of smokers (Table 3 ). The number of cigarette sticks consumed per day varies with the age of smokers. The biggest consumers are recruited in the age groups [31]-[41], [41]-[51] and [51]-[61] and the people who smoke more than 10 sticks per day constitute $50 \%$ of the smoker population (Table 4).

TABLE 2. DISTRIBUTION OF TOBACCO CONSUMERS ACCORDING TO THE METHOD OF CONSUMPTION WITH RESPECT TO AGE AND GENDER

\begin{tabular}{|c|c|c|c|c|c|c|c|c|}
\hline \multirow[b]{2}{*}{ Sex } & \multirow[b]{2}{*}{ Method } & \multicolumn{6}{|c|}{ Age range } & \multirow[t]{2}{*}{ P-value } \\
\hline & & [21-31] & [31-41] & [41-51] & [51-61] & [61-71] & $\geq 71$ & \\
\hline \multirow[t]{5}{*}{ male } & smoke & $13(20.0)$ & $7(10.8)$ & $13(20.0)$ & $12(18.5)$ & $3(4.6)$ & / & \multirow{5}{*}{0.0001} \\
\hline & applied on tooth & $2(3.1)$ & & / & 1 & 1 & / & \\
\hline & Smoke + crew & $1(1.5)$ & $1(1.5)$ & l & I & l & I & \\
\hline & Smoke + inhale & $2(3.1)$ & & & $4(6.2)$ & I & l & \\
\hline & Total & $18(27.7)$ & $8(12.3)$ & $13(20.0)$ & $16(24.6)$ & $3(4.6)$ & & \\
\hline \multirow[t]{3}{*}{ female } & smoke & 1 & 1 & 0 & $1(1.5)$ & 1 & $1(1.5)$ & \multirow{3}{*}{0.052} \\
\hline & applied on tooth & I & I & $2(3.1)$ & $3(4.6)$ & I & I & \\
\hline & Total & & & $2(3.1)$ & $4(6.2)$ & & $1(1.5)$ & \\
\hline \multirow[t]{5}{*}{ Total } & smoke & $13(20.0)$ & $7(10.8)$ & 13 & $13(20.0)$ & $3(4.6)$ & $1(1.5)$ & \multirow{5}{*}{0.0001} \\
\hline & applied on tooth & $2(3.1)$ & 1 & $2(3.1)$ & $3(4.6)$ & I & I & \\
\hline & Smoke + crew & $1(1.5)$ & $1(1.5)$ & 1 & 1 & l & l & \\
\hline & Smoke + inhale & $2(3.1)$ & 1 & I & $4(6.2)$ & I & I & \\
\hline & Total & $18(27.7)$ & $8(12.3)$ & $15(23.1)$ & $20(30.8)$ & $3(4.6)$ & $1(1.5)$ & \\
\hline
\end{tabular}

TABLE 3. DISTRIBUTION OF TOBACCO SMOKERS ACCORDING TO THE DURATION OF SMOKING WITH RESPECT TO AGE.

\begin{tabular}{llllll}
\hline Age range & $<1$ Year & $1-5$ Years & $5-10$ years & $>10$ years & Total \\
\hline$[21-31]$ & $2(4)$ & $9(18 \%)$ & $2(4 \%)$ & $1(2 \%)$ & $14(28 \%)$ \\
{$[31-41]$} & & $2(4 \%)$ & $1(2 \%)$ & $5(10 \%)$ & $8(16 \%)$ \\
{$[41-51]$} & & $1(2 \%)$ & & $11(22 \%)$ & $12(24 \%)$ \\
{$[51-61]$} & & & & $13(26 \%)$ & $13(26 \%)$ \\
{$[61-71]$} & & & & $2(4 \%)$ & $2(4 \%)$ \\
$\geq 76$ & & & & $1(2 \%)$ & $1(2 \%)$ \\
\hline Total & $2(4 \%)$ & $12(24 \%)$ & $3(6 \%)$ & $33(66 \%)$ & $50(100 \%)$ \\
\hline
\end{tabular}

TABLE 4. DISTRIBUTION OF TOBACCO SMOKERS ACCORDING TO THE NUMBER OF STICKS THEY SMOKE PER DAY WITH RESPECT TO AGE

\begin{tabular}{lccccc}
\hline $\begin{array}{l}\text { Age } \\
\text { range }\end{array}$ & $2-5$ sticks & $\begin{array}{c}5-10 \\
\text { sticks }\end{array}$ & $\begin{array}{c}\text { More } \\
\text { than } 10 \\
\text { sticks }\end{array}$ & $\begin{array}{c}\text { Not } \\
\text { determine }\end{array}$ & Total \\
\hline$[21-31]$ & $1(2 \%)$ & $6(12 \%)$ & $1(2 \%)$ & $12 \%()$ & $9(18 \%)$ \\
{$[31-41]$} & $2(4 \%)$ & & $6(12 \%)$ & & $8(16 \%)$ \\
{$[41-51]$} & $1(2 \%)$ & $3(6 \%)$ & $6(12 \%)$ & $2(4 \%)$ & $12(24 \%)$ \\
{$[51-61]$} & $4(8 \%)$ & $1(2 \%)$ & $9(18 \%)$ & $3(6 \%)$ & $17(34 \%)$ \\
{$[61-71]$} & & & $3(6 \%)$ & & $3(6 \%)$ \\
$\geq 76$ & & & & $1(2 \%)$ & $1(2 \%)$ \\
\hline Total & $8(16 \%)$ & $10(20 \%)$ & $25(50 \%)$ & $7(14 \%)$ & $50(100 \%)$ \\
\hline
\end{tabular}

B. Mouth cytology of tobacco consumers and nonconsumers

Characteristics of cellular abnormalities found on a hyperkeratotic buccal smear of individuals in the study population are represented on the figure 1. The anomalies observed on the buccal smears include parakeratotic lesions with pycnotic nuclei (Fig 1.b), abnormal keratinization of epithelial cells with or without sparingly nuclei (Fig 1.c), cells with multiple granulation (Fig 1.d), intermediate cells with active binuclearisation but a normal-sized nucleus (Fig. 1.e), epithelial cells presenting a small clear halo around the nucleus (fig.1.f), epithelial cell whose morphology suggests a tadpole appearance, in particular with a fairly apparent cytoplasmic extension, the presence' a population of filamentous elements reflecting the presence of candida species (Fig. 1.h).

The distribution of oral epithelial atypia found on tobacco hyperkeratotic buccal smears of tobacco consumers in the study population is represented in the Figure 3. From this figure, hyperorthokeratosis + hyperparakeratosis were the changes mostly seen on tobacco hyperkeratotic buccal smears (59\%), followed by hyperorthokeratosis + hyperparakeratosis + cytoplasmic granulosis $(27 \%)$ and hyperorthokeratosis + cytoplasmic granulosis were the least seen (14\%). The tobacco consumption was significantly correlated to the presence of oral epithelial cellular changes $(\mathrm{p}<0.001)$. 


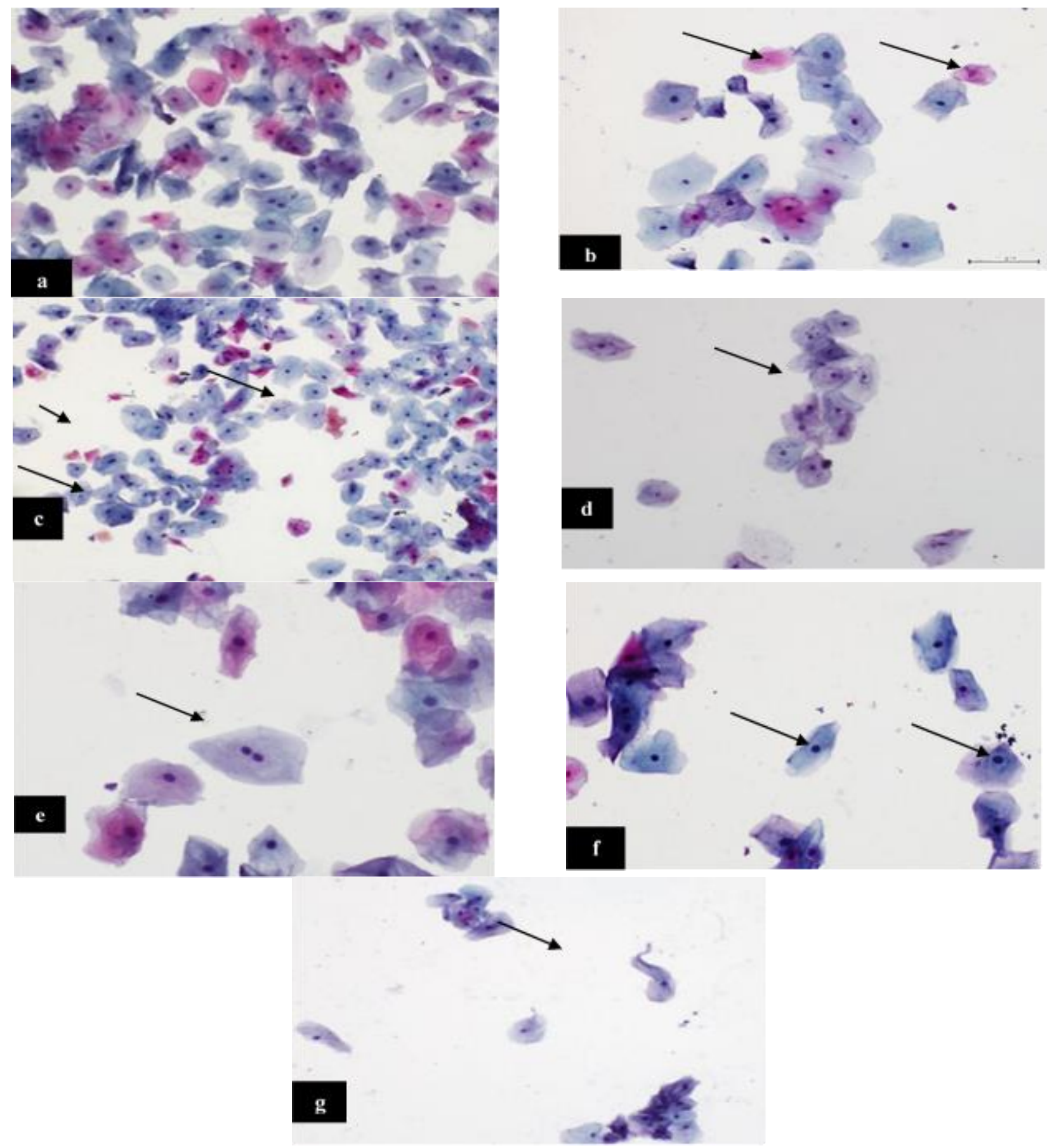

Figure 1: Cellular characteristics seen on buccal smears in the study population.

a shows cellular aspects related with a normal buccal smear. We can see a desquamation of superficial and intermediate cells strata (Pap X10). In b, the pycnotic aspect of the nucleus (arrow) in a cell with an orangeophilic cytoplasm coincides with parakeratotic lesions (Pap X40). In c, epithelial cells sometimes isolated, sometimes tattered, with cytoplasm expressing an abnormal keratinization, but with erased nuclei, are sparingly noted. These aspects coincide with benign hyperkeratosis (Pap X10). Image d shows a closet of oral cells with multiple cytoplasmic granulations. In $\mathbf{e}$ we can easily see an intermediate cell with reactive binucleation. However, nucleus retain a normal shape and size (Pap X40). Image $\mathbf{f}$ shows epithelial cells marked with a small clear halo around the nucleus (Pap X10). Image $\mathbf{g}$ shows an epithelial cell whose morphology suggests a tadpole appearance, in particular with a fairly apparent cytoplasmic extension (Pap X40). Finally, in $\mathbf{h}$, the inflammatory context marked by the presence of polynuclear cells is justified by the presence of a filamentous population of elements of the oral microflora. 


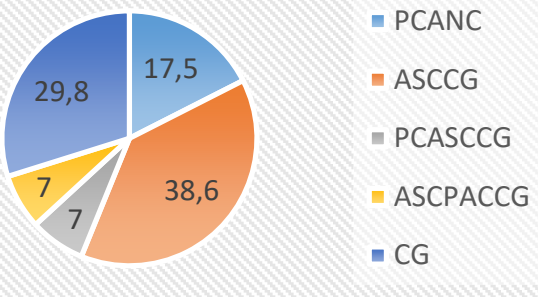

Fig. 2: Distribution of oral epithelial atypia found on hyperkeratotic buccal smears of individuals in the study population.

PCANC : parakeratotic cells and anucleate single cells, ASCCG :

anucleate single cells and cytoplasmic granulosis, PCASCCG : parakeratotic cells, anucleate single cells and cytoplasmic granulosis, ASCPACCG : anucleate single cells, Plaques of anucleate cells and cytoplasmic granulosis, CG : cytoplasmic granulosis

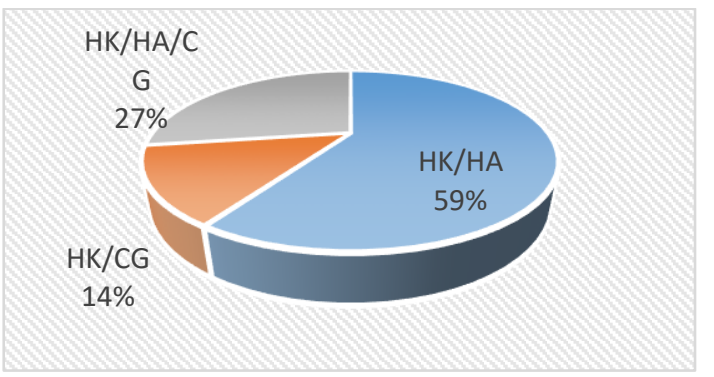

Fig. 3: Distribution of oral epithelial atypia found on tobacco

hyperkeratotic buccal smears of tobacco consumers in the study population.

C. MDA concentrations in tobacco consumers and nonconsumers

The average MDA $(0.28 \pm 0.163)$ in the mouth of tobacco users with Tobacco hyperkeratosis was significantly higher $(p<0.001)$ than that of those who did not have this abnormality. Overall, levels of MDA in the mouth of nontobacco users was significantly lower than among consumers. The majority of non-tobacco users had low MDA levels (between 0.010 and $0.25 \mu \mathrm{M} / \mathrm{ml}$ ). On the other hand, even if the majority of smokers also presented values of MDA contained in this range, it is in this group that high rates of MDA $(>0.25)$ were observed, with a cumulative percentage of $16.7 \%$.

The average MDA in the mouth of tobacco consumers with hyperkeratosis was significantly higher than in those who did not have thus abnormality. Overall, the level of MDA in the mouths of our tobacco consumers was significantly lower than in consumers.

TABLE 5. INFLUENCE OF TOBACCO CONSUMPTION ON SALIVA MDA LEVEL IN PARTICIPANTS TO THE STUDY

\begin{tabular}{|c|c|c|c|c|}
\hline & \multicolumn{2}{|c|}{ Consumers } & \multicolumn{2}{|c|}{ Non-consumers } \\
\hline $\begin{array}{l}\text { Oral epithelial } \\
\text { cellular changes }\end{array}$ & $\mathrm{N}$ & $\begin{array}{c}{[\mathrm{MDA}] \pm \mathrm{SD}} \\
(\mu \mathrm{M} / \mathrm{ml})\end{array}$ & $\mathrm{N}$ & $\begin{array}{c}{[\mathrm{MDA}] \pm \mathrm{SD}} \\
(\mu \mathrm{M} / \mathrm{ml})\end{array}$ \\
\hline Normal & 10 & $0.13 \pm 0.110^{\mathrm{a}}$ & 19 & $0.10 \pm 0.066^{*}$ \\
\hline Hyperkeratosis & 21 & $0.16 \pm 0.101^{\mathrm{a}}$ & 26 & $0.09 \pm 0.069 *$ \\
\hline $\begin{array}{l}\text { Tobacco } \\
\text { hyperkeratosis }\end{array}$ & 25 & $0.28 \pm 0.163^{b}$ & $\mathbf{0}$ & I \\
\hline $\begin{array}{l}\text { Non-specific } \\
\text { inflammatory } \\
\text { changes }\end{array}$ & 6 & $0.19 \pm 0.153$ & 5 & $0.10 \pm 0.086^{*}$ \\
\hline Oral microflora & 3 & $0.16 \pm 0.103^{\mathrm{a}}$ & 5 & $0.08 \pm 0.047 *$ \\
\hline
\end{tabular}

\section{IV.DISCUSSION}

Tobacco, because of the nicotine it contains, is a drug. Nicotine addiction is as powerful as that caused by cocaine and heroin due to the combination of physical and psychological dependence. Whether the situation is pleasant or unpleasant, smoking makes the user feel good. This phenomenon pushes consumer to continue using tobacco to feel the same well-being. As smoking declines in developed countries, its prevalence increases in developing countries. This is the case in Cameroon, where the smoking prevalence rate is around $17.5 \%$ including $28.8 \%$ men and $8.1 \%$ women [23]. In this study, the prevalence of tobacco use was very high $(54.1 \%)$ and this prevalence was higher in men $48.3 \%)$ than in women $(5.8 \%)$, contrasting with others published results in Cameroon. For instance, Pefura et al. [24], got a prevalence of $8.4 \%$ in adult peoples in Yaoundé. Working conditions in the travailing agencies in Bafoussam is very difficult and may explain this high rate of tobacco consumption by the employers. According to a Dares analysis, the work environment sometimes encourages employees to light a cigarette more easily. Physical constraints, heavy loads, exposure to noise, cold, heat, humidity, dirt, fear of losing one's job are aggravating factors of smoking [24]. All these factors are encountered in the visited travelling agencies in Bafoussam.

The trend of tobacco consumption in males based on their ages was; the highest $(31.0 \%)$ level of consumption was among younger adults (aged between 21-31 years), higher (27.6\%) among males aged between 54-64 years, high (22.4\%) among male aged 43-53 years and lowest among older adults (aged between 65-75 and 76-86 years). It shows that tobacco consumption is fast increasing among young adults. This is in contrast with Fred Pampel's study [25] on tobacco use in sub-Sahara Africa among men aged 15-54 years and women aged 15-49 years in 14 nations, where he found that, male cigarette smokers are more likely to be older. Inhaling and chewing tobacco were methods least used by the study population. These results coincide with previous studies [26] where they found that the predominant use of tobacco is by smoke inhalation of cigarettes, pipes, and cigars.

The present study showed a statistical significance between tobacco consumption and oral epithelial abnormalities $(\mathrm{p}<0.001)$. In line with the study carried out by Seifi et al. [11], Shetty et al. [12] and Divyasri et al. [13], increase in keratinized cells (tobacco hyperkeratosis) was present only on buccal smears of tobacco consumers (cases). Hussain et al. [14] had similar findings, they found that smokers with clinically normal mucosa show a greater percentage of keratinized cells and a greater nucleolar activity, suggesting that cigarette smoking influences the cellular activity of the mucosa. The increase in the size of the nucleus as observed in some participant to his study may be related to the increased amount of DNA required for cell replication. The reduction in cytoplasmic in smokers can be attributed to dehydration which is a kind of cell adaptation in 
response to the decrease in fluids, especially saliva around the cell [11].

It was noticed an increased number of hyperkeratosis (characterized by parakeratosis, cytoplasmic granulosis, anucleated single cells) in the control group (non-consumers). This important increase may be due to systemic diseases, age related cellular modifications [15] or the effect of other agents or substances on buccal squamous cells like alcohol, hot meals, peppers [4] which could lead to keratinization of cells. The presence of keratinization supports the fact that exposure to alcohol and other agents affects the pattern of maturation in oral mucosal cells [16].

Non-specific inflammatory changes with increased inflammatory cells, which infiltrated were observed in both groups in this study; this increase might be a result of epithelial irritation caused by smoking and other irritating substances. Such a finding was previously reported [17]. Cigarette smoke has effects on saliva, oral commensal bacteria, and fungi, mainly Candida, which causes oral candidiasis, the most common opportunistic fungal infection in man [18] and how cigarette smoke affects oral Candida is still controversial.

Saliva being the first biological fluid met by external substances ingested as food, drinks, inhaled volatile cigarette smoke, microorganisms, it represents the first line of defense against oxidative stress [27]. Oxidative stress represents the imbalance between the production of highly reactive molecular species (ROS, reactive nitrogen species) and antioxidant defense systems [28]. In the present work, the concentration of MDA in saliva was significantly higher in smokers compared to non-smokers, like the results reported by [19] who showed that oxidative stress is increasing in the smoker. This elevation can be explained by the increase in the number of inflammatory cells in the oral cavity that releases large quantities of anion superoxide and hydrogen peroxide by various mechanisms. The present study shows a significantly higher mean MDA concentration in tobacco consumers compared to non-consumer, and we notice an increased mean MDA concentration in individuals with tobacco hyperkeratotic changes on their buccal smears. These results are similar to those of Rashmi and Saumya [29]. Increases in MDA levels (in saliva and serum) are not only due to tobacco consumption, but also as a consequence of the magnitude of oxidative stress, supporting the hypothesis that cancer cells have markedly altered ROS metabolism, leading to production of large amounts of ROS as compared to nonneoplastic cells, and the suppression of the antioxidant system that mediate body's defense mechanisms [30].

Tobacco use is one of the important causes of death and a leading public health problem worldwide [8]. Tobacco use is considered one of the risk factors for oral cancer.

\section{CONCLUSION}

Based on the results of the present study which had as general objective to determine the effect of tobacco on oral epithelial cells and on the oxidant/antioxidant balance in the oral cavities of participants in the study population, we can conclude that tobacco consumption severely increases the risk for developing oral mucosal proliferative lesions, and the level of oxidative stress in the saliva of individuals in the study population.

\section{ACKNOWLEDGMENT}

The authors express their deep appreciation to the people who voluntarily agreed to participate in this study despite their work constraints. They also thank the heads of the travel agencies for their cooperation and for the cordial welcome they extended to them.

\section{REFERENCES}

[1] World Health Organisation (2016). Global Health Observatory (GHO) data. Prevalence of tobacco smoking. Available at http://www.who.int/gho/tobacco/use/en

[2] Ahmed, H. G. (2013). Etiology of oral cancer in the Sudan. J Oral Maxillofac Res, 4, e3

[3] Alshammari, F.D., Khalifa, A.M. and Kosba, A.A. (2015). Assessment of Perception of medical students in regard to links between tobacco or alcohol use and cancer. Asian Pac J Cancer Prev. vol: 16, pp:2697-2700.

[4] Ahmed, H.G and Babiker, A.A. (2009). Assessment of cytological atypia, AgNOR and nuclear area in epithelial cells of normal ora mucosa exposed to toombak and smoking. Rare tumors. Vol:1, pp:234-236.

[5] Parkin, D.M., Bray, F., Ferlay, J. and Pisani, P. (2005). Global cancer statistics, 2002. CA Cancer J Clin. Vol:55, pp:74-108. [PubMed]

[6] Linda, C. N. and Gretchen, G. (2007). The geriatric patient in Treatment Planning in Dentistry (Second Edition).

[7] Wigand, J.S. (2006). Additives, cigarette design and tobacco product regulation. A report to WHO, Tobacco Free Initiative and Tobacco Product Regulation Group. Kobe-Japan. P: 12-13.

[8] Balfour, D.J.K. (2015). The role of mesoaccumbens dopamine in nicotine dependence. Curr Top Behav Neurosci. Vol:24 pp:55-98.

[9] Cunningham, F.H., Fiebelkorn, S., Johnson, M. and Meredith, C. (2011). "A novel application of the Margin of Exposure approach: segregation of tobacco smoke toxicants". Food Chem. Toxicol. Vol: 49 pp: 2921-2933.

[10] Miller, K.P. and Ramos, K.S. (2001). Impact of cellular metabolism on the biological effects of benzo[a]pyrene and related hydrocarbons. Drug Metab Rev. vol:33, pp:1-35.

[11] Seifi, S., Feizi, F., Mehdizadeh, M., Khafri, S. and Ahmedi, B. (2014) Evaluation of cytological alterations of oral mucosa in smokers and water-pipe users. Cell J. vol;15, pp:302-309.

[12] Shetty, R., Mukherjee, S., Dutta, N., Bhagat, D.K., Sushma, K. N. and Pandey, V. (2016). Cytomorphometric analysis of oral squames tobacco smoker's using oral brush biopsy: An exfoliative cytological study. IAIM. Vol:3, pp:14-9.

[13] Divyasri, G., Rashmi, N., Ahmed, M., Praveen, K.G., Smitha, V. and Mukund, N. (2018). Tobacco-induced alterations in exfoliated oral epithelial cells: A comparative image analysis study. Journal of Dr. NTR University of Health Sciences. Vol: 7, pp: 168-173.

[14] Hussain, G.A., Syda, O.M., Ali, E., Mohmmed, O.M.H. and Afra, Y.A.G. (2012). Oral Epithelial Atypical Changes in Apparently Healthy Oral Mucosa Exposed to Smoking, Alcohol, Peppers and Ho Meals, Using the AgNOR and Papanicolaou Staining Techniques. Diagnostic Cytopathology. Vol 38, p: 7489.

[15] Montgomery, P.W. (1951). A study of exfoliative cytology of normal human oral mucosa. J Dent Res. vol;30, pp:12-8. 
[16] Burzlaff, J.B., Bohrer, P.L., Paiva, R.L., Visioli, F., SantAna, M.F., da Silva, V.D. and Rados, P.V. (2007). Exposure to alcohol or tobacco affects the pattern of maturation in oral mucosal cells: a cytohistological study. Cytopathology. Vol;18, pp:367-375.

[17] Luomanen, M., Tiitta, O., Heikinheimo, K., Leimola-Virtanen, R., Heinaro, I. and Happonen, R.P. (2006). Effect of snuff and smoking on tenascin expression in oral mucosa. J Oral Pathol Med. Vol ;26, pp:334-338.

[18] Soysa, N.S. and Ellepola, A.N.B. (2005). The impact of cigarette/tobacco smoking on oral candidosis: an overview. Oral Dis. vol;11, pp:268-273.

[19] Jain, A., Agrawal, B.K., Varma, M. and Jadhav, A.A. (2009). Antioxidant status and smoking habits: relationship with diet. Singapore Med J. vol:50, p:624.

[20] Atasayar, S., Orhan, H. and Özgünefi, H. (2004). Malondialdehyde quantification in blood plasma of tobacco smokers and non-smokers. FABAD J Pharm Sci. vol;29, pp:15-9.

[21] Esterbauer, H., Cheeseman, K.H., Dianzani, M.U., Poli, G., and Slater, T.F. (1982). Determination of Aldehydic Lipid Peroxidation Products: Malonaldehyde and 4-Hydroxynonenal. Biochem. J. vol;208, p:129.

[22] Papanicolaou, G.N. (1960). Classification of cytologic diagnosis. Chapter 5 in oral exfoliative cytology, Veterans Administration Cooperation Study.

[23] Mbatchou, N., Bertrand, H., Ekobo, H. and Kuaban, C. (2015).

[24] Prevalence and determinants of cigarette smoking among college students. A cross sectional study in Douala Cameroon. Archives of Public Health. Vol 73 .

[25] Eric, W.P., Adamou, D.B., Boris, J.T., Emmanuel, A.Z. and Christopher, K. (2016). Prevalence et facteurs associés au tabagisme a yaoundé, Cameroun. Journal of medicine and health sciences. Vol. 17.

[26] Fred, Pampel. (2008). Tobacco use in sub-Sahara Africa: Estimates from the demographic health surveys. Soc Sci Med. Vol 66, pp: 72-83.

[27] Bahrani, A.J.A. (2013). Evaluation of the cytological changes of oral mucosal cells in Smokers by using exfoliative Pap Stain. MDJ. Vol:10, pp:124-129.

[28] Battino, M., Ferreiro, M.S. and Gallardo, I. (2002). The antioxidant capacity of saliva. J Clin Periodontol. Vol: 29, pp: 189-194.

[29] Halliwell, B. (2007). Biochemistry of oxidative stress. Biochemical Society Transactions. Vol:35 pp:1147-1150.

[30] Rashmi, M. and Saumya, B. (2014). Evaluation of salivary and serum lipid peroxidation, and glutathione in oral leukoplakia and oral squamous cell carcinoma. Journal of Oral Science, Vol. 56, pp:135142.

[31] Sheetal, K. C., Minal, C., Amol, R. G., Aparna, S. and Satyajit, T. (2013). Oxidative and antioxidative mechanisms in oral cancer and precancer: A review. Elsevier Ltd. All rights reserved.

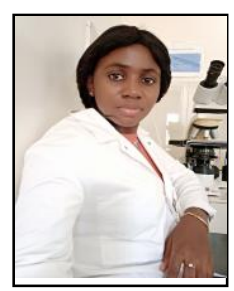

KAMBOU KOUNTCHOU Keriane Diane born in Bafoussam West Region of Cameroon on the $3^{\text {rd }}$ of August 1993. Diane's primary education was done in Standard English School Bafoussam west region of Cameroon where she obtained her first school living certificate in 2003. Her secondary and higher education was done in Presbyterian Secondary School Nkwen Bamenda, North West region of Cameroon, where she obtained her GCE ordinary.

Level in 2009 and GCE Advanced level in sciences in 2011. In 2015, Diane obtained a Higher Professional Diploma in Dental Therapy and in 2016 a Bachelor degree in Dental Therapy both at St Louis Institute of Health and Biomedical Sciences Bamenda North west Cameroon. She obtains a Masters degree in Clinical Cytopathology in 2019 at Evangelical University of Cameroon Bandjoun, West region of Cameroon. She has participated in many oral health educational campaigns and outreaches in the North West and west regions of Cameroon, taught at St. Louis University Institute and Tchonang Institute in the Dental therapy departments and at the HND level of Evangelical University of Cameroon. Presently, she works at the anatomy pathology laboratory of the Bafoussam regional hospital as a CYTOPATHOLOGIST. She is currently interested in research on lymph node pathologies and tuberculosis. She has carried out research on malocclusion and orthodontic treatment needs in Bamenda.

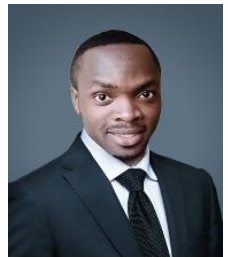

Mr. TAMUEDJOUN was Born in Bafoussam (West Cameroon) on January 08, 1994. Obtained a Bachelor's Degree in biomedical sciences and a Master's Degree in clinical cytopathology respectively in 2014 and 2016 at the Evangelical University of Cameroon (Bandjoun City).

He worked first as an academic monitor and then as a lab manager. Deputy coordinator of the master's in cytopathological and histopathological technologies, he occupies this function at the same time as academic assistant for the monitoring of teachings at the Faculty of Science and Technology at the Evangelical University of Cameroon. He is particularly interested in gynecological cytology and the technical quality of the preparations (Douala, Cameroon: Alaric TALOM, 2019).

Mr. TAMUEDJOUN is the West-Cameroon regional focal point of the CAREHF (Cameroon Research and Health Forum) and is one of the first graduates in clinical cytology sub-Saharan in Africa where he works to make the specialty known to the population and health professionals

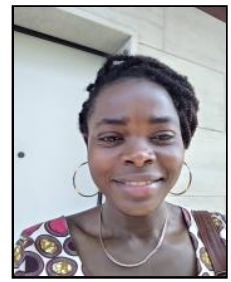

DEUTOU WONDEU Andrillene Laure born in Banka West Region of Cameroon on the $09^{\text {th }}$ of February1986. Laure's primary education was done in notre dame de Banka school in west region of Cameroon where she obtained her first school living certificate in 1997. Her secondary and higher education was done in classical high school of Bafang, west region of Cameroon, where she obtained her Bachelor's degree in 2004. In 2009, Laure obtained a Bachelor in biochemistry in University of Yaoundé I and a Master's degree in health sciences/immunology at Catholic University of Central Africa in Yaoundé center of Cameroon.

Since December 2016 she is Adjunct laboratory director at the academic's laboratories of practical work at the Evangelical University of Cameroon. In addition, she teaching courses in immunology, bacteriology, hematology and laboratory techniques at the Higher Institute of Applied Sciences for Health in Bafoussam since October 2015. She received additional training in molecular biology and biotechnology and she has knowledge of the use of instruments like Rotor-Gene Q, Drew-3 (3-part differential automatic hematology system), CytoFlex, KEYLAB automatic analyzer, MagPurix 24 nucleic acid extraction system, PCR thermal cyclers, spectrophotometer... She is $\mathrm{PhD}$ student in immunology, molecular biology and applied biotechnology, in University of Rome Tor Vergata, since November 2018. 